\title{
Problems with the bedbug (Cimex lectularius) in Slovakia
}

\author{
Anna Totkova ${ }^{1, A-F}{ }^{\oplus}$, Adrian Totka ${ }^{2, A-D \oplus}$, Ludmila Sevcikova ${ }^{3, A, C-F} \oplus$, Lubica Argalasova ${ }^{3, A-F} \oplus$, \\ Anna Cibulkova ${ }^{4, A, D-E \oplus}$, Martin Simko ${ }^{2, A, D-F} \oplus$ \\ ${ }^{1}$ Faculty of Medicine and University Hospital, Institute of Medical Biology, Genetics and Clinical Genetics, Comenius \\ University, Bratislava, Slovak Republic \\ ${ }^{2}$ Faculty of Medicine and University Hospital, 2nd Clinic of Gynecology and Obstetrics, Comenius University, Bratislava, \\ Slovak Republic \\ ${ }^{3}$ Faculty of Medicine, Institute of Hygiene, Comenius University, Bratislava, Slovak Republic \\ ${ }^{4}$ Faculty of Medicine, Institute of Foreign Languages, Comenius University, Bratislava, Slovak Republic \\ A - Research concept and design, B - Collection and/or assembly of data, C - Data analysis and interpretation, \\ $D$ - Writing the article, $E$ - Critical revision of the article, $F$ - Final approval of article
}

Totkova A, Totka A, Sevcikova L, Argalasova L, Cibulkova A, Simko M. Problems with the bedbug (Cimex lectularius) in Slovakia. Ann Agric Environ Med. 2019; 26(3): 400-404. doi: 10.26444/aaem/103898

\begin{abstract}
Introduction. In the 1970s and 1980s, the occurrence of bedbugs (Cimex lectularius Linnaeus, 1758) was noticed only sporadically in accommodation facilities in Slovakia. Under regular monitoring, it was possible to even eradicate its occurrence in the 1980s. Today, the problem is once again a major global health issue.

Objective. The aim of the study was to point out the occurrence of cimicosis in the case of atypical urticaria in patients referred to parasitological examination by inpatient and outpatient physicians.

Material and methods. During the period 2006-2015, 102 patients with suspected ectoparasitosis were examined in the Diagnostic Laboratory of Human Parasitology at the Faculty of Medicine of Comenius University in Bratislava. Specialists and general practitioners referred the patients with itching red efflorescences. Parasitological examination and entomologic analysis of insects confirmed in many of them the presence of skin ectoparasitosis caused by Cimex lectularius, and in one case Oeciacus hirundinis.

Results. A total number of 102 parasitologically patients were examined - 62 adults and 40 children. Among the 62 adults, there were 57 patients positive for cimicosis. In 5 patients cimicosis was not confirmed, in one of them (Sarcoptes scabiei Linnaeus, 1758) was detected. Among the 40 children, there were 34 positive for cimicosis. One female child was diagnosed with lesions caused by Sarcoptes scabiei.
\end{abstract}

Conclusions. The bed bug should again be subjected to the reporting service to public health authorities, and thus recording the monitoring of its incidence and spread in the population.

\section{Key words}

prevention, tourism, ectoparasites, Cimex lectularius, cimicosis

\section{INTRODUCTION}

Arthropods are the most numerous groups of animals. Many of them live as ectoparasites parasitizing on animals and humans. One of the species that occurs in our geographic zone is a bedbug (Cimex lectularius Linnaeus, 1758). Its biological development and activity are linked to the human habitat $[1,2,3]$.

The Cimicidae (bedbug) is a widespread cosmopolitan family comprising 25 genera and more than 90 species. They feed mainly on the blood of birds and bats $[1,4]$. Of these, about 7 species are blood-sucking insects also on humans. Two species, tropical bedbug (Cimex hemipterus Fabricius, 1802) and bedbug (C. lectularius), definitively abandoned their original hosts and parasitize only on man $[1,3,5,6]$. A bedbug (C. lectularius) has better adaptation capabilities than a tropical bug (C. hemipterus); therefore, it has gradually spread to all continents except for Antarctica [7].

The swallow bug (Oeciacus hirundinis) can also be an occasional ectoparasite of man, an ectoparasite of swallow

Address for correspondence: Lubica Argalasova, Comenius University, Faculty of Medicine, Institute of Hygiene, Bratislava, Slovak Republic

e-mail: lubica.argalasova@fmed.uniba.sk

Received: 14.09.2018; accepted: 11.02.2019; first published:08.03.2019 birds of all kinds. Swallows or house martins usually build their nests on residential houses. In the autumn, after their flight departure for warm countries, bugs migrate from the nests to human dwellings [2]. Blood is vital for bedbug as it is the only source of food and water. It can manage to trace the host from its hiding place over a distance of $150 \mathrm{~cm}$. The temperature of the skin, kairomones and exhaled $\mathrm{CO}_{2}[8,9]$ are enough to find the host. During prolonged starvation and massive spread in the environment, its habits can change. In sleeping people, it sucks blood on various exposed parts of their body (hands, feet, neck, face, and trunk). The pattern of feeding is characterized by $2-3$ bites in an irregular line (Fig. 1). It ceases to be photophobic; it does not fear normal daylight or even artificial light. In such a case, the sleeping individual may be attacked not only at night but also during the day. It was found that children and women are more often at risk than men, which is probably related to the thickness of the host's skin.

During the day, bedbugs cluster together in hiding places which are closest to the man; thus, they belong to gregarious insects. Currently, there is evidence that bedbug incidence and spread does not depend directly on hygienic standards of the environment [10]. The obvious sign of the presence of bedbugs in an apartment are dark brown faecal droplets 
with the remnants of undigested blood in the hiding places (paintings, furniture, wallpapers, wooden panels, folds in the upholstery, mattresses, etc.) and bed linen. They can last without feeding for a very long time, in a warmly heated room for 35 days. At low temperature, their starvation can last for as long as $1-2$ years $[2,4,10,11]$.

If a person has never come into contact with bedbugs before, the first skin reaction occurs 3-7 days following the bite. It emerges as a small, red macular lesion with a diameter of less than $5 \mathrm{~mm}$, which later can enlarge into a papular rash about $2-6 \mathrm{~cm}$ in size, persisting longer than 24 hours (Fig. 1). The lesions spontaneously disappear within 2-6 weeks [12]. Bedbug bites, with their appearance and symptoms, are similar to hives (urticaria cimicina). Itchy or even burning and long-lasting skin reactions are hardly distinguishable from the bite of other insects (fleas, lice, mosquitoes, etc.) [13]. In severe infestation, macules and papules may merge to form a generalized rash which itches heavily, and with constant scratching by a sufferer, it can also alter its appearance. In rare cases, there may develop vesicles and bullae $[14,15,16]$. In sites often attacked by scratching, there can also develop a secondary bacterial infection [17]. It is usually considered to be a skin disease of different origin, while the health condition of the patient deteriorates.

The physician prescribes the patient antihistamines and even corticosteroids, not taking into consideration the fact that it may be a case of bedbug occurrence in the apartment. During this treatment period, there already occurs the reproduction of bugs. The cause of the incidence of urticaria is often confirmed only when the apartment has already been infested by bugs $[2,7,15]$. Other health problems related to the infestation by bedbugs are insomnia, nightmares, fatigue, hallucinations, depression, asthma, anaphylactic shock, anemia, and others [13, 14, 18, 19].

The resulting lesions on the skin after bedbug bites heal up to 3 weeks, sometimes with post-inflammatory hyperpigmentation. Some people respond to bites by a

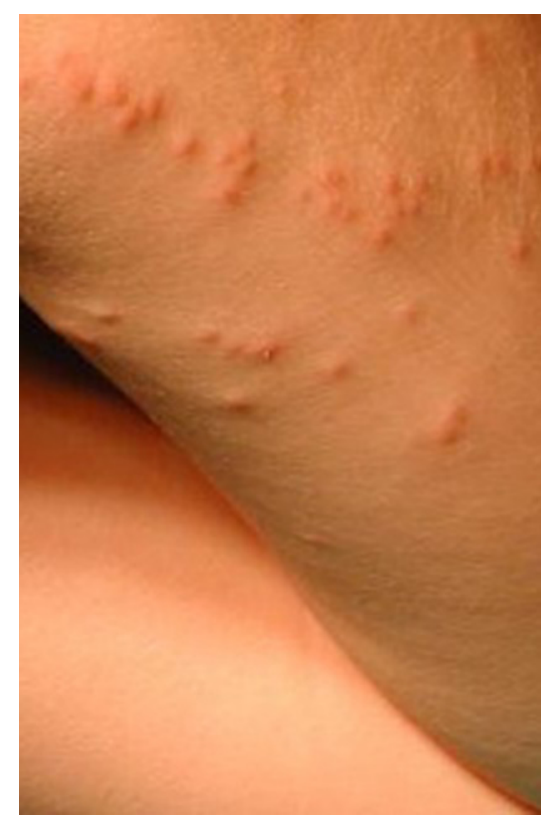

Figure 1. Urticaria cimicina on the forearm of a patient after being bitten by Cimex lectularius, diagnosed in the laboratory. Reproduced with the patient's consent. pronounced reaction, whereas others are insensitive to bug bites (about 20\%) [7, 15].

Before confirming the presence of bugs in an apartment, nowadays, there can be detected specific IgE against antigens of bedbugs in patients with cimicosis symptoms. These are found in the saliva (nitrophorin) of a sufferer [20]. In addition to a specific IgE, in papular urticaria, the production of IgG antibodies has been shown [21].

The biology of bugs may also play an important role in the transmission of infectious agents. Imagines and nymphs feed on sucking the blood not only in humans but also in domestic poultry, dogs, cats, and bats. In the saliva, digestive tract and faeces of bugs, there more than 40 different pathogens have been detected, for which the possibility of transmission to humans is not yet proven $[14,22]$. Concerning viral diseases, there was a confirmed bedbug-borne presence of the hepatitis $B$ virus and HIV which dies in the digestive tract of bugs $[23,24]$. However, there has been no evidence so far that the mentioned pathogens would multiply in bugs. In such a case, bedbugs also cannot transmit infectious agents to their hosts. Supposedly, bedbugs only serve as vectors of these pathogens $[5,22,25,26]$.

In the 1970s and 1980s, the occurrence of bedbugs was noticed only sporadically in apartments, family houses, and accommodation facilities in Slovakia and the Czech Republic. Under regular monitoring of the situation by hygienists, it was possible not only to eliminate the occurrence of bedbugs, but in the 1980s even to eradicate them. Nowadays, in the 21 st century, this worldwide major public health concern has occurred once again in Slovakia $[10,27]$ and the Czech Republic [7, 28].

\section{OBJECTIVE}

The aim of the study was to point out the occurrence of cimicosis in the case of atypical urticaria in patients referred to parasitological examination by inpatients and being faced once again.

\section{MATERIAL AND METHODS}

During the period 2006-2015, 102 patients with suspected ectoparasitosis were examined in the Diagnostic Laboratory of Human Parasitology at the Faculty of Medicine at the Comenius University (FMCU) in Bratislava, Slovakia. The group included 62 adults (48 females and 14 males) and 40 children (30 girls and 10 boys).

Within differential diagnosis insect bites (fleas, Pediculus humanus, mosquitoes, C. lectularius, and others), were taken into account, or infestation by intestinal geohelminths and Protozoa whose toxins can cause an allergic reaction in the form of various skin alterations (urticaria, macules, papules, etc.).

After a thorough visual inspection of the patient's body and affected areas with erythematous-urticarial lesions with a diameter of 5-10 $\mathrm{mm}$, it was found that their arrangement on the skin occurred more or less in lines, therefore ruling out that they were caused by a mosquito, flea, or Pediculus humanus bite (Fig. 1). After pressing a glass slide on the skin lesion, there was clearly seen a haemorrhagic dot in the centre of the bite [15], which confirmed that it was an insect bite, 
C. lectularius bite in particular, due to the distribution of lesions. In cases where patients brought a suspected insect, a thorough entomological analysis was carried out, first macroscopically and then under a binocular magnifier. In the material analyzed, all developmental stages (eggs, nymphs, imagines - both males and females) of the bedbug (C. lectularius) were diagnosed. In one case, the occurrence of a swallow bug (O. hirundinis) directly from a well-known source (a swallow's nest above the window) was confirmed. From a number of suspected insects brought, there were 25 C. lectularius and one O. hirundinis.

In 2 cases, Sarcoptes scabiei (Linnaeus, 1758) was detected. The parasite can be found on the skin in small blebs or corridors. In this parasitological examination, the keratin layer of the skin was broken by a $10 \%$ solution of potassium hydroxide $(\mathrm{KOH})$ on a cotton swab, which was allowed to act on the skin for 2 minutes in adults and one minute in children. The macerated layer of the skin was then scraped off with a scalpel, and the specimen applied to a drop of water on a slide and examined microscopically [15].

By parasitological examination of patients and entomologic analysis of insect brought by patients, confirmed clearly in many of them that it was skin ectoparasitosis (cimicosis) caused by a $C$. lectularius.

\section{RESULTS}

Among the 102 examined patients with suspected ectoparasitosis, there were $60.8 \%$ of adults and $39.2 \%$ of children. Among 62 adult patients with skin erythematousurticarial lesions, there were 57 (91.9\%) positive for cimicosis (Tab. 1). This ectoparasitosis developed after bedbug (C. lectularius) bite, and in one case by swallow bug (O. hirundinis) bite. In the other $5(8.1 \%)$ patients, ectoparasitosis (cimicosis) was not confirmed. In one adult patient S. scabiei was detected. Among the 57 patients with cimicosis, there were 3 with confirmed anaemia, 6 with asthma, and 10 patients were treated for various forms of allergy by an immunoallergist (lactose intolerance, glutenrelated disorders, histamine intolerance, skin rash, etc.). All patients, in addition to severe itching and burning of the skin in sites bitten by bedbugs, suffered from insomnia, fatigue, irritability, depression, and in their opinion, they could not even concentrate on the job at work.

Of 40 examined children who had erythematous-urticarial skin lesions, there were 34 (85\%) positive for ectoparasitosis (cimicosis). One female child was diagnosed with lesions caused by the sarcoptic mite (S. scabiei). Of 34 children

Table 1. Diagnostic results of ectoparasitoses in the Laboratory of Human Parasitology of the FM CU in Bratislava, Slovakia

\begin{tabular}{lccccc}
\hline & \multicolumn{5}{c}{ Patients examined } \\
\cline { 2 - 6 } Ectoparasites & Number & $\begin{array}{c}\text { Occurrence } \\
(\%)\end{array}$ & Number & $\begin{array}{c}\text { Occurrence } \\
(\%)\end{array}$ & Number \\
\cline { 2 - 6 } & 56 & 96.6 & 34 & 97.1 & 90 \\
\hline Cimex lectularius & 1 & 1.7 & 0 & 0 & 1 \\
\hline Oeciacus hirundinis & 1 & 1.7 & 1 & 2.9 & 2 \\
\hline Sarcoptes scabiei & 58 & 100 & 35 & 100 & 93 \\
\hline Total & 58 &
\end{tabular}

Occurrence (\%) - percent of total count adults and children; Number - number of patients with cimicosis, there were 2 with anaemia, 8 with asthma, and 15 patients were treated for various forms of allergy (urticaria, lactose intolerance, histamine intolerance, glutenrelated disorders, and even intolerance to certain foods) by an immunoallergist. In addition to severe itching and burning of the skin in sites bitten by bedbugs, the children suffered particularly from insomnia, irritability, fatigue, and lack of concentration, which in some of them, according to the statements by their mothers, interfered with school performance. Specialists (immunoallergists, gynecologists, dermatologists, gastroenterologists, etc.) and general practitioners for children and adults, sporadically referred the patients with various incurable skin heavily itching red efflorescences to parasitological consultations. Other patients with a similar diagnosis sought medical advice themselves. Their poor health kept impairing their lives, and the patients suffered not only physically but also mentally. Prescribed antihistamines, corticosteroids, mebendazole, aluminum acetate, calamine lotion with menthol, ALPA embrocation, camphor spirit, and marigold ointment, managed to reduce severe itching of skin efflorescences partially, the rashes gradually healed, but new ones appeared on the face, neck, torso, hands, and legs.

Diagnostic issues are exemplified by the following selected cases. Five female university students of medicine staying in a dormitory, asked our laboratory to help with their skin problems. They had the same skin alterations after insect bites, experienced severe itching and burning of the skin caused by the raised erythematous-urticarial lesions with a diameter of 5-6 mm (Fig. 1). Unbearable itching prevented them from sleeping. They were tired; some had a fever and could not even concentrate on learning. Every third or fourth day they found new skin urticaria. A university doctor thought that it was a food allergy or a kind of factor of the environment. The thorough examination of efflorescences on the skin and their characteristic distribution on the body confirmed that it was a $C$. lectularius bite and cimicosis. The students who were adequately informed brought to the laboratory all developmental stages of bugs (eggs, nymphs, imagines bedbugs) which they had found in the seams and folds of bed mattresses. The insects brought were entomologically inspected, and it was confirmed that they were C. lectularius.

The patients reported different sites of infestation with C. lectularius, 35 patients in their own apartments (blocks of flats) and family houses, dormitories (5 patients), also holidays in various destinations of Europe (Italy, France, Germany, Greece, Poland, Czech Republic, Hungary - 43 patients), as well as recreation in North and East Slovakia (7 patients) (Tab. 2). Some patients brought the bugs in

Table 2. Sites of infestation with Cimex lectularius in patients examined in the Diagnostic Laboratory of Human Parasitology at the Faculty of Medicine, Comenius University (FMCU) in Bratislava, Slovakia

\begin{tabular}{lcc}
\hline Sites of infestation & Number & Occurrence (\%) \\
\hline Own apartments (blocks of flats), family houses & 35 & 38.5 \\
\hline Dormitories & 5 & 5.5 \\
\hline Holidays in various destinations of Europe & 43 & 47.2 \\
\hline Recreation in North and East Slovakia & 7 & 7.7 \\
\hline Asylum center for mothers with children & 1 & 1.1 \\
\hline Total & 91 & 100 \\
\hline
\end{tabular}

Occurrence (\%) - percent of total count of patients; Number - number of patients 
clothes packed in the luggage, which after returning home were put away into wardrobes, and were unpacked with some delay. In one case, it was also a hostel at the asylum centre for mothers with children. In the other patients with unconfirmed cimicosis, in 2 cases S. scabiei was detected.

All patients with cimicosis were warned of the need for disinfection of their entire apartment, family house, university dorm, as well as hostels at the asylum center for mothers with children, by a pest control company that performs such a service. Patients with the result of parasitological and entomological examinations were referred to their attending physician to manage their further treatment.

\section{DISCUSSION}

The results showed that the incidence of ectoparasite $C$. lectularius in human dwellings is not as rare as 40 years ago, when by continuous monitoring of the incidence of this ectoparasite in Slovakia, it was not only managed but even eradicated $[7,27,29]$. In the 1980s, the incidence of bedbugs in Bratislava was not noted because since the 1960 s in Slovakia this ectoparasitosis it has been obligatory to report its occurrence, like other serious and health-threatening endoparasitoses. Employees in public health (hygiene services) in Slovakia have had this infestation under constant surveillance, and strict health regulations and measures to prevent the occurrence and spread of this ectoparasitosis have been applied. There was a law on furniture and equipment control when moving into a new apartment or house, or when moving to another city. In the case of detection of C. lectularius infestation in furniture and equipment, uncompromisingly there was ordered a total disinfection of the entire apartment. After checking the effectiveness of decontamination, and when no viable eggs, nymphs, and imagines were found in furniture, equipment and throughout the apartment, the family could move into the new premises or to another city upon receipt of the certificate issued by the hygienist. These laws and health measures prevented an epidemic and even endemic uncontrolled spread of the bedbug further in residential complexes, houses, hotels, hostels, dormitories, etc.

To-date, there are no eradication plans in the fight against bedbugs [27, 30, 31]. It is necessary reimplement them in all health facilities according to the relevant recommendations. Studies clearly indicate that this is a worldwide health problem $[30,32,33]$. C. lectularius, which from the health point of view, causes very unpleasant ectoparasitosis (cimicosis) in humans, should again be subjected to obligatory reporting to the public health authorities, as in the past, in order to underpin better the monitoring of its incidence and prevalence in the population $[27,30,31]$.

Situations similar to those described by the patients living in apartments of the blocks of flats from various housing estates in Bratislava, described in the current study, have also described by other authors $[25,28,31,34]$.

The incidence and spread of this ectoparasite worldwide are increasing endemically $[25,28,31]$. Physicians in practice cannot provide substantive treatment for people affected by bedbugs. Thus, researchers investigated whether ivermectin (a relatively inexpensive and safe oral anti-parasitic drug) is capable of killing bedbugs after a blood meal from such a treated host. The results of the study showed that an anti- parasitic drug caused a relatively high bedbug mortality $(98 \%$ for $260 \mathrm{ng} / \mathrm{mL}$ ivermectin and $0 \%$ for $0 \mathrm{ng} / \mathrm{mL}$ ivermectin after 13 days) [35].

Although dogs are also used to detect bugs in many other countries worldwide [14, 36], Slovakia is the first country in Europe which has specially trained certified dogs for searching out bugs. They can find bugs by olfactory clues, first, by responding to the pheromones and faecal droplets of bugs. They can find whole nests of bugs in the furniture and equipment of an apartment. At present, most of the C. lectularius population is resistant to organophosphates, pyrethroids and carbamates, which are mostly used in attempts to kill them [28]. Resistance has also been confirmed to neonicotinoids [37]. However, the use of organophosphates is forbidden in the EU; for C. lectularius control, a mixture of deltamethrin and pyrethrum piperonyl butoxide is recommended [28].

Currently, to control crawling insects (C. lectularius, cockroaches, etc.) specialized professional companies in Slovakia and the Czech Republic use the biocidal, highly active insecticidal preparations chlorfenapyr and alphacypermethrin, which have a broad range of action and an excellent residual activity $[38,39]$. Due to their mode of action, within the anti-resistant strategy, using these agents synergistically is recommended.

Given the high risk posed to human health, C. lectularius requires special attention from the viewpoint of environmental health experts as well as the general population.

\section{CONCLUSION}

The presented results indicate the current danger arising from the spread of ectoparasites. The modernization of human dwellings in cities, nor in countries with a high standard of living and culture, has not resulted in the elimination of bedbugs. It is obvious that the cases cited above were not only sporadic, but will have rather an increasing occurrence. The fight against bedbugs is more difficult as people do not know about them, or feel embarrassed to admit they have them in their apartment. Also, there is no health education in the media for the general public drawing attention to this growing problem. Therefore, it is again essential to pay the same attention to this ectoparasitosis as to other endoparasitoses, in order for them not to be underestimated and forgotten in medical practice.

\section{Acknowledgements}

The research was funded by the Faculty of Medicine at Comenius University in Bratislava, Slovakia.

\section{Conflict of interest}

The authors declare they have no conflicts of interest in the publication of this study.

\section{REFERENCES}

1. Kadlubowski R, Czapliński B, Dymowska Z, Kurnatowska A, Lachmajer J, and Pawlowski Z. Zarys parazytologii lekarskiej: podręcznik dla studentów medycyny. Warszawa, Państwowy Zakład Wydawnictw Lekarskich; 1979 [in Polish].

2. Totková A, Klobušický M, Valent M. Medical Parasitology. Martin, Osveta s.r.o.; 2008 [in Slovak]. 
3. Foulke GT, Anderson BE. Bedbugs. Seminars in Cutaneous Medicine and Surgery 2014; 33: 119-22.

4. Mullen GR, Durden LA. Medical and Veterinary Entomology, Second Ed. Amsterdam: Academic Press Elsevier; 2009.

5. Delaunay P, Blanc V, Del Giudice P, Lery-Bencheton A, Chosidow O, Party P, Brouqui P. Bedbugs and Infectious Diseases. Clin Infect Dis. 2011; 52: 200-210.

6. Khan HR, Rahman M. Morphology and biology of the bedbug, Cimex hemipterus (Hemiptera: Cimicidae) in the laboratory. Dhaka University J Biol Sci. 2012; 21: 125-130.

7. Jedličková $H$. The bedbug-return uninvited guest. Dermatologie pro praxi 2011; 5: 196-198 [in Czech].

8. Anderson JF, Ferrandino FJ, Mc Knight S, Nolen J, Miller J. A carbon dioxide heat and chemical lure trap for the bedbug Cimex lectularius. Med Vet Entomol. 2009; 2: 99-105.

9. Harraca V, Ryne C, Birgersson G, Ignell R. Smelling your way to food: can bedbugs use our odour? J Experimental Biol. 2012; 215: 623-629.

10. Kočišová A. The occurrence of bedbug (Cimex lectularius) in Eastern Slovakia. Dezinfekce Dezinsekce Deratizace 2006; 15 [in Slovak].

11. Reinhardt K, Siva-Jothy MT. Biology of the bedbugs (Cimicidae). Annual Rev Entomol. 2007; 52: 351-374.

12. Reinhardt K, Kempke D, Naylor RA, Siva-Jothy MT. Sensitivity to bites by the bedbug, Cimex lectularius. Med Vet Entomol. 2009; 23: 163-6.

13. Goddard J, de Shazo R. Bedbugs (Cimex lectularius) and clinical consequences of their bites. J Am Med Assoc. 2009; 301: 1358-66.

14. Doggett SL, Dwyer DE, Peñas PF, Russell RC. Bedbugs: clinical relevance and control options. Clin Microbiol Rev. 2012; 25: 164-92.

15. Buchvald J, Buchvald D. Dermatovenerology. Bratislava: SAP - Slovak Academic Press s.r.o; 2002. [in Slovak].

16. de Shazo R D, Feldlaufer MF, Mihm MC Jr, Goddard J. Bullous reactions to bedbug bites reflect cutaneous vasculitis. Am J Med. 2012; 125: 688-694.

17. Lowe CF, Romney MG. Bedbugs as vectors for drug-resistant bacteria. Emerging Infect Dis J. 2011; 17: 1132-1134.

18. Paulke-Korinek M, Széll M, Laferl H, Auer H, Wenisch C. Bedbugs can cause severe anaemia in adults. Parasitol Res. 2012; 110: 2577-9.

19. Price JB, Divjan A, Montfort WR, et al. IgE against bedbug (Cimex lectularius) allergens is common among adults bitten by bedbugs. J Allerg Clin Immunol. 2012; 129: 863-865.

20. Leverkus M, Jochim RC, Schäd S, Bröcker EB, Andersen JF, Valenzuela JG, et al. Bullous Allergic Hypersensitivity to Bedbug Bites Mediated by IgE against Salivary Nitrophorin. J Investigative Dermatol. 2006; 126: 91-96.

21. Abdel-Naser MB, Lotfy RA, Al-Sherbiny MM, Sayed Ali NM. Patients with papular urticaria have IgG antibodies to bedbug (Cimexlectularius) antigens. Parasitol Res. 2006: 550-556.

22. Lai O, Ho D, Glick S, Jagdeo J. Bedbugs and possible transmission of human pathogens: a systematic review. Arch Dermatol Res. 2016; 308: 531-538.
23. Blow JA, Turell MJ, Silverman AL, Walker ED. Stercorarial shedding and transtadial transmission of hepatitis B virus by common bedbugs (Hemiptera: Cimicidae). J Med Entomol. 2001; 38: 694-700.

24. Jupp PG, Lyons SF. Experimental assessment of bedbugs (Cimex lectularius and Cimex hemipterus) and mosquitoes (Aedes aegypti formosus) as vectors of human immunodeficiency virus. AIDS 1987; 1: $171-174$.

25. Zorrilla-Vaca A. Bedbugs and Vector-Borne Diseases. Clin Infect Dis. 2014; 59: 1351-1352.

26. Zorrilla-Vaca A, Silva-Medina MM, Escandon-Vargas K. Bedbugs, Cimex spp.: their current world resurgence and health care impact. Asian Pacific J Tropical Dis. 2015; 5: 342-352.

27. Totková A, Šimaljaková $M$, Pretová O, Hlavačiková $H$, Klobušický $\mathrm{M}$, Valent M, et al. Cimicosis - again current problem (in Slovak). In: Labuda days, Bratislava, Institute of Virology SAV; 2009: pp. 113-114.

28. Rupeš V. Bedbugs are current in our country. Zprávy epidemiológie a mikrobiológie (Epidemiology and microbiology news) 2009; 18: 17-18 [in Czech].

29. Jírovec O, Jíra J. Parasitologie pro lékaře. Praha, Avicenum; 1977 [in Czech].

30. Thomas S, Wrobel MJ, Brown J. Bedbugs: a primer for the health system pharmacist. Am J Health-System Pharmacy 2013; 15: 126-30.

31. Kuhn C, Van der Pan. The worldwide expansion of bedbugs also constitutes a problem in Germany. Bundesgesundheitsblatt 2014; 57: 524-530.

32. Wang C, Saltzmann K, Chin E, Bennett GW, Gibb T. Characteristics of Cimex lectularius (Hemiptera: Cimicidae), infestation and dispersal in a high-rise apartment building. J Economic Entomol. 2010; 103: 172-177.

33. Vaidyanathan R, Feldlaufer MF. Bedbug Detection: Current Technologies and Future Directions. Am J Tropical Med Hygiene 2013; 88: 619-625.

34. Lee IY, Ree HI, An SJ, Linton JA, Yong TS. Reemergence of the bedbug Cimex lectularius in Seoul, Korea. Korean J Parasitol. 2008; 46: 269-71.

35. Sheelm JM, Anderson JF, Tran TD, Teng YA, Byers PA, Ravi BS, et al. Ivermectin causes Cimex lectularius (bedbug) morbidity and mortality. J Emerg Med. 2013; 45: 433-40.

36. Pfiester M, Koehler PG, Pereira RM. Ability of bedbug - detecting canines to locate live bedbugs and viable bedbug eggs. J Economic Entomol. 2008; 101: 1389-1396.

37. Romero A, Anderson TD. High Levels of Resistance in the Common Bedbug, Cimex lectularius (Hemiptera: Cimicidae), to Neonicotinoid Insecticides. J Med Entomol. 2016; 53: 727-731.

38. DDD Servis Slovakia. https://www.dddservis.sk/etiketa/E_Mythic\%20 10\%20SC.pdf (access: 2018. 12. 06.)

39. DDD Servis Slovakia.http://www.dddpresov.sk/files/E-FENDONA_6SC. pdf. (access: 2018. 12.06.)

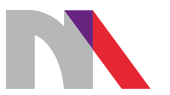

Ministry of Science and Higher Education

Republic of Poland

Generation of the DOI (Digital Object Identifier) - task financed under the agreement No. 618/P-DUN/2019 by the Minister of Science and Higher Education 